\title{
TAMAN REKREASI DAN PUSAT INFORMASI PARIWISATA DI JAKARTA
}

\author{
Henry Suryadi Arthen ${ }^{1)}$, Diah Angraini ${ }^{2)}$ \\ 1) Program Studi S1 Arsitektur, Fakultas Teknik, Universitas Tarumanagara, arthenhenry@gmail.com \\ 2) Program Studi S1 Arsitektur, Fakultas Teknik, Universitas Tarumanagara, diah_ismono@yahoo.com
}

\begin{abstract}
Abstrak
Kota Jakarta memiliki sejarah yang panjang yang membuat Jakarta memiliki banyak objek wisata seperti Monumen Nasional, Gelora Bung Karno, Kota Tua. Di antara lokasi wisata itu terdapat banyak objek wisata lainnya yang sudah hilang atau ditinggalkan. Salah satunya adalah Taman Ria Senayan. Taman Ria Senayan merupakan salah satu ruang terbuka yang sangat diminati di tahun 70an, tetapi ruang publik ini kini hanya tersisa di ingatan masyarakat walaupun berada di tengah kawasan perkotaan yang padat. Untuk dapat mengembalikan wisata yang hilang ini diperlukan sebuah konsep arsitektur yang dapat memfasilitasi keinginan dan kebutuhan para wisatawan. Architourism merupakan sebuah istilah baru di dunia arsitektur, dengan menjadikan arsitektur sebagai wadah bagi objek wisata, dampak yang diberikan dari architourism diyakini dapat mempengaruhi tingkat ekonomi sebuah perkotaan. Bentuk pendekatan yang digunakan adalah membuat program wisata baru yang dapat meningkatkan aktivitas wisatawan di kawasan tersebut. Dengan melakukan analisis dan mempelajari antara arsitektur dan wisata ini makan diusulkan proyek sebuah Taman Rekreasi dan Visitor Center di Taman Ria Senayan. Visitor Center ini akan berfungsi sebagai pusat informasi mengenai pariwisata dan menjadi pintu masuk dalam sebuah kawasana wisata. Dengan adanya Visitor Center ini diharapkan agar baik masyarakat dan wistawan dapat mengetahui lebih banyak tentang tujuan wisata yang ada di Jakarta dan membantu dalam upaya konservasinya.
\end{abstract}

Kata kunci: hutan kota, Taman Ria Senayan, wisata, waterfront

\begin{abstract}
Moumen Nasional, Gelora Bung Karno and Kota Tua. on the other hand a lot of tourist attraction that lost it place in the world and one of them are Taman Ria Senayan. Taman Ria Senayan is one of favorite public place in the 70's but now all that's left is only the memory in some people eventhough its located in the center of a city. An architecture is needed to bridge the need and desire of a toursit. Architourism is a new term where architecture becoming the main object of tourist attraction. Archtourism have the power to increase economy of the city. Th design approach that the writer take is to make a new programtic design that is new in the metropolic area. Based on the analysis and research the writer decided to propose a Recreation Park and Visitor Center in Taman Ria Senayan. Visitor Center will be functionate as a information center and a gate for tourist area. With the existence of the Visitor Center, it is expected that both the community and tourists can find out more about tourist destinations in Jakarta and help in their conservation efforts.
\end{abstract}

Keywords: visitor centre, Taman Ria Senayan, tourism, waterfront, urban forest.

\section{PENDAHULUAN}

Kota metropolitan berdasarkan fungsinya merupakan kota yang menjadi pusat kegiatan, dari pemerintahan, perdagangan, dan industri. Sebagai pusat dari perkantoran, perdagangan, dan pemerintahan dan Ibukota Negara Jakarta adalah salah satu kota yang diminati oleh para wisatawan. Menurut data dari https://jakarta.bps.go.id dari 8 juta wisatawan yang datang ke Indonesia sebanyak 2 juta wisatawan memilih Jakarta sebagai tempat wisatanya. Pariwisata merupakan salah satu sektor prioritas yang memiliki peran penting dalam kegiatan perekonomian suatu negara. Bahkan sektor pariwisata melebihi sektor migas serta industri 
lainnya apabila dikelola dengan baik. Dengan demikian, banyak negara di dunia untuk berlomba-lomba mengembangkan potensi-potensi pariwisata yang dimilikinya sebagai upaya untuk meningkatkan pendapatan negara (Yoeti, O. 2008: 1).

Pada kenyataannya Jakarta masih belum bisa mengelola pariwisatanya dengan baik, dengan banyaknya tempat tempat wisata yang di punya oleh jakarta hanya beberapa tempat yang menjadi perhatian wisatawan. Untuk mendukung kebutuhan di atas dibutuhkan sebuah perancangan visitor center. Kehadiran visitor center akan berfungsi sebagai sarana promosi dan informasi wisata, tidak hanya menyediakan informasi mengenai dunia wisata saja Visitor Center juga menyediakan data tentang kebudayaan lokal dan potensi alam yang dimilikinya. Visitor center juga dapat menjadi salah satu objek wisata itu sendiri, sebaiknya visitor center berada di tempat yang strategis dan dilalui oleh bus wisata.

Permasalahan yang diangkat oleh penulis pada perancangan ini adalah sebagai berikut:

- Bagimana proyek ini dapat membantu dalam perkembangan pariwisata jakarta?

- Program apa saja yang dapat mengundang wisatawan untuk datang ke sebuah tempat wisata?

Adapun tujuan dari perancangan adalah:

- Menghasilkan perancangan Arsitektur sebuah pusat informasi pariwisata dengan pendekatan architourism.

- Meningkatkan minat masyarakat untuk mengunjungi objek wisata di Jakarta. Manfaat yang diharapkan dari perancangan ini adalah sebagai berikut:

- Meningkatkan angka pariwisata di Jakarta.

- Memberikan pengetahuan mengenai budaya lokal betawi.

- Untuk menjadi sebuah tempat wisata kota yang baru.

\section{KAJIAN LITERATUR}

\section{Wisata Perkotaan}

Ciri utama kota metropolis dapat dlihat dengan tingkat kependudukan di atas satu juta jiwa, mobilitas dan akitivas penduduk yang kompleks dan tingkat ekonomi yang tinggi. Kawasan metropolis adalah sebuah sistem jaringan antar kota yang terkoneksi dengan kota intinya yang berada di pusat. Dengan banyaknya berbagai macam sektor ekonomi yang tersebar membuat kawasan metropolis harus mempunyai tingkat mobilitas yang tinggi. Salah satu sektor ekonomi yang yang berkembang pesat adalah di bagian pariwisata kota.

Wisata perkotaan telah menjadi salah satu daya tarik sebuah kota, kota yang memiliki banyak situ bersejarah atau monumen peninggalan masa lalu akan lebih menarik wisatawan untuk datang berkunjung. Posisi geografis sebuah kota juga mempunyai nilai strategis dalam daya jangkau wisatawan. Jakarta adalah salah satu kota yang terkoneksi baik antar kota di dalam Jawa dan di luar Jawa. Pentingnya fasilitas yang di sediakan di kota juga menjadi faktor penentu untuk wisatawan, seperti kenyamanan sistem transportasinya, penyajian taman kota, kebersihan dan keamanan pribadi, fasilitas menginap, objek rekreasi, dan tempat belanja yang di tawarkan. Makanan lokal juga menjadi magnet untuk wisatawan terutama wisatawan mancanegara karena bisa lebih diterima oleh masyarakat international.

Dalam perkembangannya banyak kota yang ikut mengembangkan wisata perkotaannya. Ada beberapa hal yang membuat kota itu gagal dalam menarik wisatawan seperti kurangnya atraksi alam, tidak adanya image kota, buruknya sanitasi, pelayanan yang kurang bervariasi seperti tidak adanya gedung pertunjukan atau opera. Hal tersebut dapat ditanggulangi dengan menciptakan festival internasional yang terencana, program wisata yang baru, pelayanan informasi yang terpercaya, dan city tour dengan jadwal yang teratur. 


\section{Visitor Center}

Menurut I Gusti Bagus Rai Utama pada makalah Fungsi dan Perencanaan Visitor Center Pariwisata Daerah, visitor center adalah sebuah fasilitas publik dengan ruang fisik yang menyediakan informasi yang terpercaya dan akurat, yang dapat menjadi simbol bagi komunitas atau kawasan dan mempunyai nilai komersil. Visitor Center mempunyai fungsi sebagai berikut

- Promosi: menyediakan informasi yang akurat dan menstimulasi permintaan wisatawan untuk menaikkan tingkat pengeluaran.

- Orientasi dan Peningkatan Kunjungan: berkonsentrasi pada kualitas pengalaman pengunjung dan menunjukkan lokasi lokasi baru yang diminati wisatawan.

- Kontrol dan Penyaringan: mengontrol aliran wisatawan dan menjadi sebagai pintu masuk ke sebuag tempat wisata.

- Substitusi: visitor center menjadi daya tarik objek wisata itu sendiri.

- Tambahan: sebagai fasilitas masyarakat untuk tempat pelaksanaan festival dan budaya lokal, dalamnya dapat terjadi penambahan fungsi seperti ruang teater dan menjadi symbol dari sebuah kawasan.

Dalam penerapannya perancangan untuk visitor center dapat dibagi menjadi beberapa bidang. Secara ekologis visitor center harus dapat mengadaptasi gaya arsitektur setempat dan menggunakan bahan lokal dengan sistem bangunan yang efisien. Secara fungsi dapat dengan menggunakan model yang statis, dinamis dengan audio visual yang menarik dan interaktif, pengunaan warna dan pencahayaan untuk menciptakan suasana hati yang berbeda. Secara tematik dengan melihat potensi dan konteks lingkungan yang diterapkan pada sebuah konsep dan ide.

\section{METODE}

Metode perancangan yang digunakan dalam perancangan ini berupa:

- Studi Literatur: digunakan untuk mempelajari lebih dalam mengenai architourism, standart ruang, dan perkotaan

- Studi Preseden: digunakan untuk mengetahui karakteristik dari visitor center dan kebutuhan ruang yang dimilikinya.

- Pengamatan Lingkungan: untuk mempelajari kondisi keadaan sekitar tapak dan luasan tapaknya yang disesuaikan dengan rencana tata ruang.

- Metode perancangan yang digunakan dengan melakukan analisis dari program aktifitas yang dijadikan konsep perancangan dengan pendekatan teoritis architourism.

\section{DISKUSI DAN HASIL}

\section{Penentuan Tapak}

Pada tahun 1970 Taman Ria Senayan adalah sebuah ruang terbuka favorit para anak muda untuk bersantai dan berkumpul bersama teman. Di tapak ini juga merupakan tempat lahir dari Grup Srimulat, seiring berjalannya waktu tapak ini mulai sepi dan di tinggalkan lalu pada tahun 1990 Taman Ria Senayan diubah untuk menjadi sebuah taman hiburan. Perubahan ini membuat Taman Ria banyak kehilangan daerah hijaunya karena perkerasan untuk taman hiburan tersebut, tetapi usaha ini gagal untuk menarik pengujung dan menghilankan suasana khas Taman Ria tersebut.

Tapak ini dipilih karena lokasinya yang strategis sebuah pusat kota berada di depan Gelora Bung Karno (GBK) dan dilewati oleh baik bus wisata dan Transjakarta. Yang diinginkan oleh perancang adalah untuk mengembalikan ruang hijau publik tersebut dan mengembangkan potensi alam tapak. 


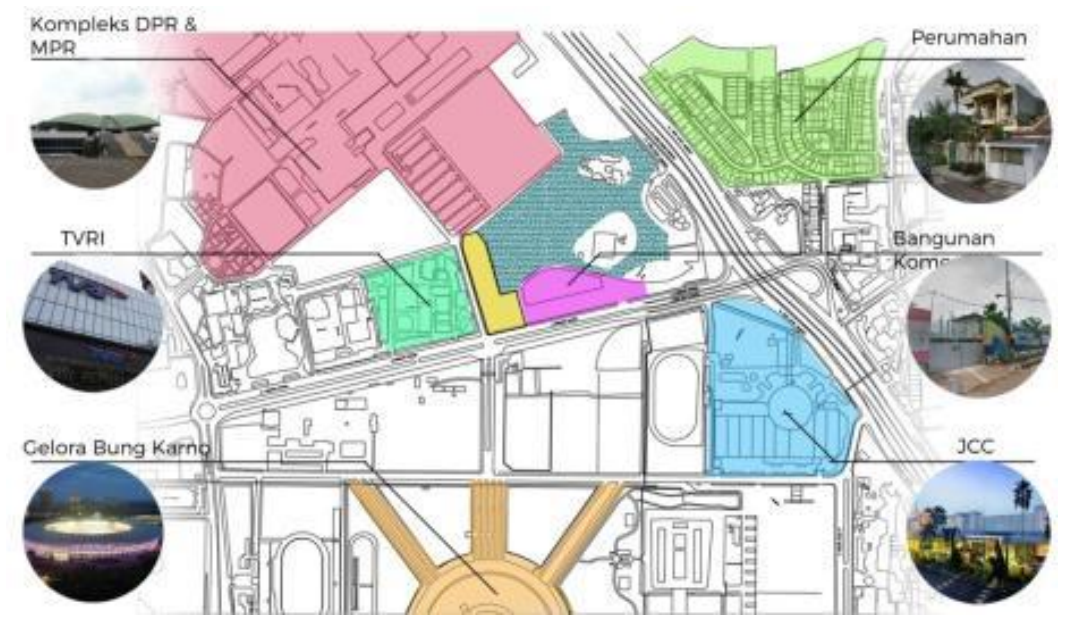

Gambar 1. Letak Tapak dan Kondisi Lingkungan Sekitar Sumber:Olahan penulis, 2018

\section{Program, Aktivitas, dan Konsep Visual Ruang}

Program dibentuk dengan melihat potensi alam yang dimiliki oleh tapak, oleh karena itu program di tapak ini lebih berorientasi kepada kegiatan di ruang luar. Pada bagian depan tapak terdapat tiga akses masuk untuk pedestarian, kendaraan pribadi dan bus. Letak pedestarian disesuaikan untuk dapat menyambut pengunjung yang berasal dari GBK, Transjakarta, dan Bus wisata.

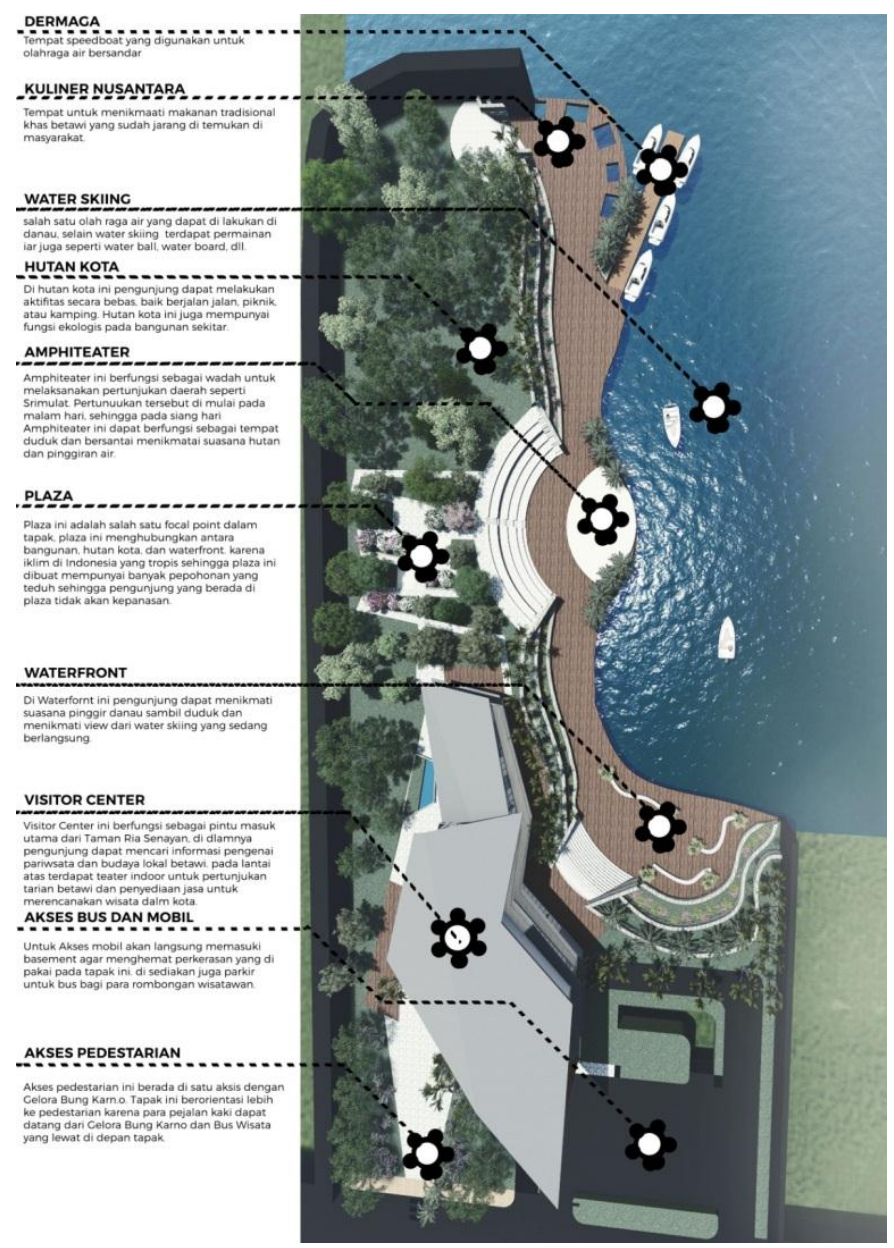

Gambar 2. Programatik

Sumber:Olahan penulis, 2018 
Masuk ke dalam tapak pengunjung akan melihat visitor center sebagai objek utama tapak yang berfungsi sebagai pintu masuk utama ke dalam tapak. Visitor center ini pengunjung dapat mencari informasi mengenai pariwisata baik dengan verbal atau menggunakan komputer. Pada lantai satu visitor center ini memiliki zona publik dan dapat beroperasional 24 jam agar para pengunjung dapat mengakses informasi secara penuh. Lantai dua terdapat galleri mengenai tempat wisata di kota jakarta, restaurant indoor dan kantor jasa. Kantor ini pengunjung dapat berkonsultasi dan merencanakan tour wisata dalam kotanya. Lantai tiga merupakan zonasi yang lebih privat dan hanya bisa di akses dengan menggunakan lift, di lantai tiga ini terdapat teater indoor yang mementaskan pertunjukan seni tradisional yang berkapasitas seratus orang. dibagian belakang massa yang menghadap ke danau juga dibuat sebuah teras untuk pengunjung dapat menikmati view dari tapak secara keseluruhan.

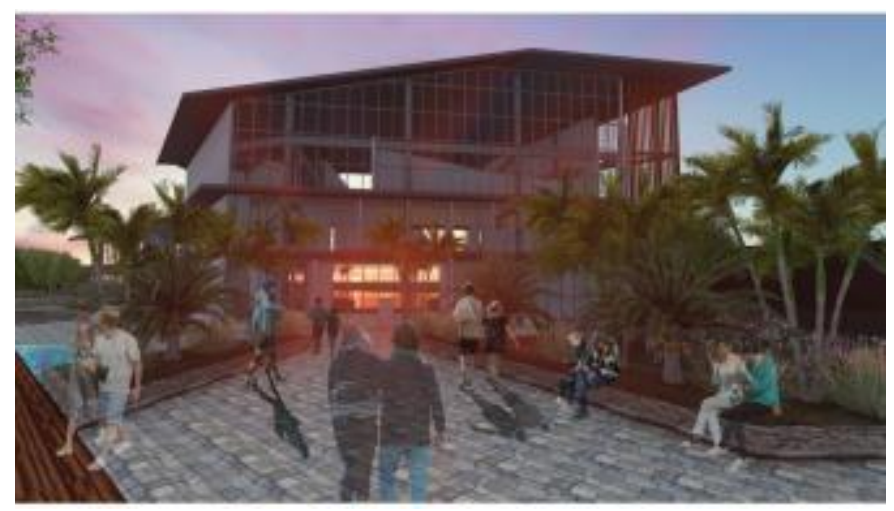

Gambar 2. Pintu Masuk Visitor Center

Sumber: Olahan penulis, 2018

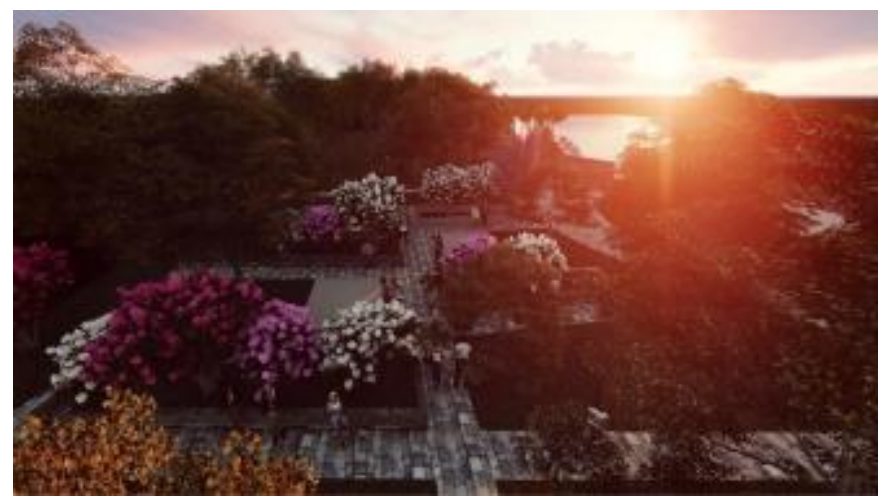

Gambar 3. Plaza

Sumber: Olahan penulis, 2018

Dari visitor center pengunjung dapat memilih untuk melakukan wisata alam hutan kota atau wisata air di pinggiran danau. Di hutan kota pengunjung dapat melakukan rekreasi dan piknik bersama keluarga, di sepanjang hutan kota ini pengunjung akan menemukan beberapa tempat yang menyediakan kuliner lokal dan pertunjukan musik tradisional. dibagian tengah dari tapak ditempatkan sebuah plaza yang dapat dijadikan titik acara ketika ada festival kebudayaan sehingga para pengunjung dapat ikut berpartisipasi dalam acara tersebut. Jika pengunjung memilih untuk melakukan wisata air pengunjung dapat mengaksesnya dengan menggunakan tangga yang di sediakan di tiga tempat, di visitor center, Plaza, dan di bagian belakang tapak. Waterfront ini pengunjung dapat duduk bersantai menikmati suasana tepian air atau berolah raga di sepanjang pinggiran danau. Pengunjung juga dapat melakukan rekreasi air seperti bermain water skiing, water board, water ball di danau tersebut. Dibagian tengah dari waterfront diletakkan sebuah amphiteater, pada siang hari amphiteater ini dapat menjadi 
tempat pengunjung untuk duduk bersantai dan pada malam harinya amphiteater ini diadakan pertunjukan tradisional khas Betawi yang bisa dinikmati oleh para pengunjung.

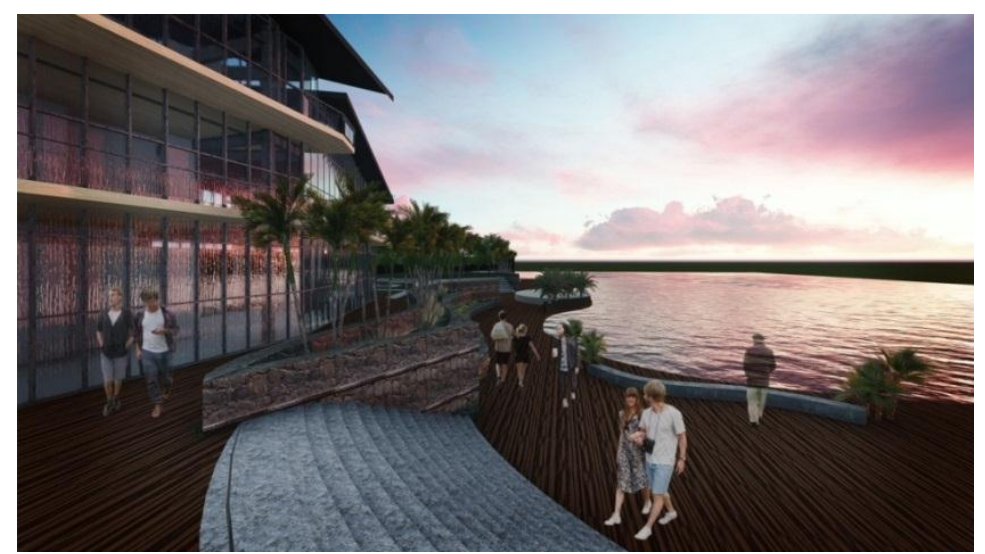

Gambar 3. Area Waterfront

Sumber: Olahan penulis, 2018

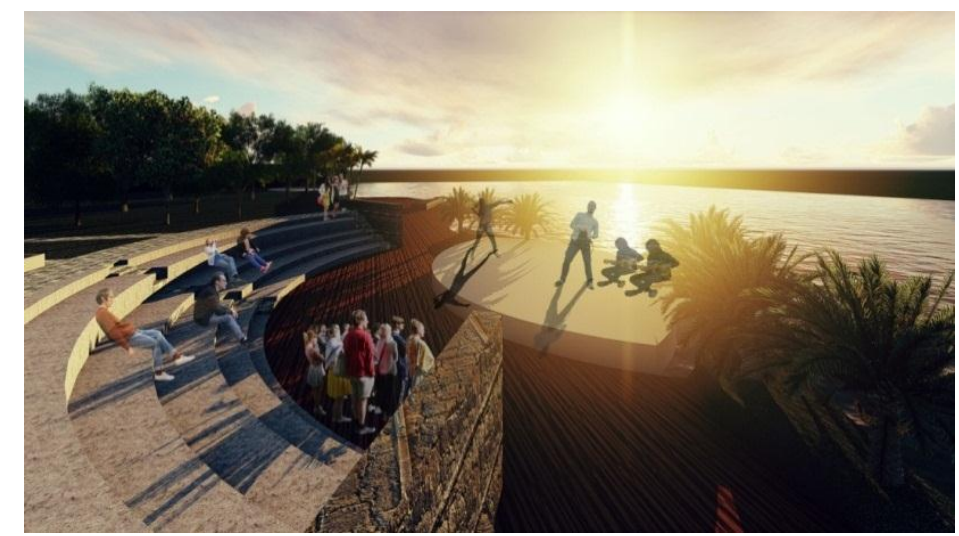

Gambar 4. Area Amphiteater

Sumber: Olahan penulis, 2018

\section{Zoning}

Pada bagian depan tapak dibuat banyak ruang terbuka untuk melayani para pejalan kaki yang datang, untuk zonasi servis di letakkan pada bagian kiri tapak yang bersebelahan dengan bangunan 4 lantai di sebelahnya. Visitor center diletakkan dibagian sudut tapak karena mempunyai view yang terbaik, lalu akses kendaraan dibuat dengan sependek mungkin untuk meminimalisir perkerasan di tapak. Zonasi tapak ini dapat di lihat seperti gambar di bawah.

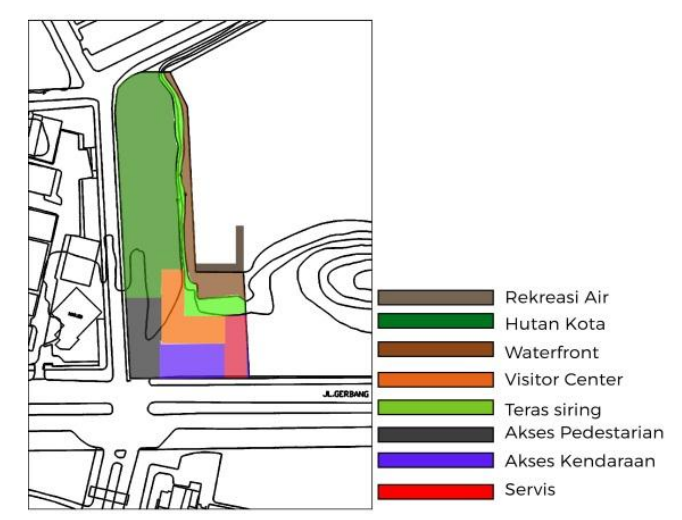

Gambar 5. Zoning

Sumber:Olahan penulis, 2018 


\section{Konsep Sirkulasi Menuju Tapak}

Pintu masuk tapak ini berada pada jalan kolektor Gerbang Pemuda, di jalan ini terdapat tiga akses masuk yaitu untuk pedestarian, kendaraan umum, dan bus. Proyek ini ingin lebih berorientasi kepada kendaraan publik, oleh karena itu pedestarian di tapak ini lebih diutamakan. Untuk meminimalisir penggunaan perkerasan di tapak, sirkulasi kendaraan di tapak ini akan langsung dimasukkan ke dalam basement. Oleh karena itu lobby untuk kendaraan berada pada lantai basement 1 dan pada lantai dasar akan sebuah ruang terbuka untuk menyambut para pejalan kaki.

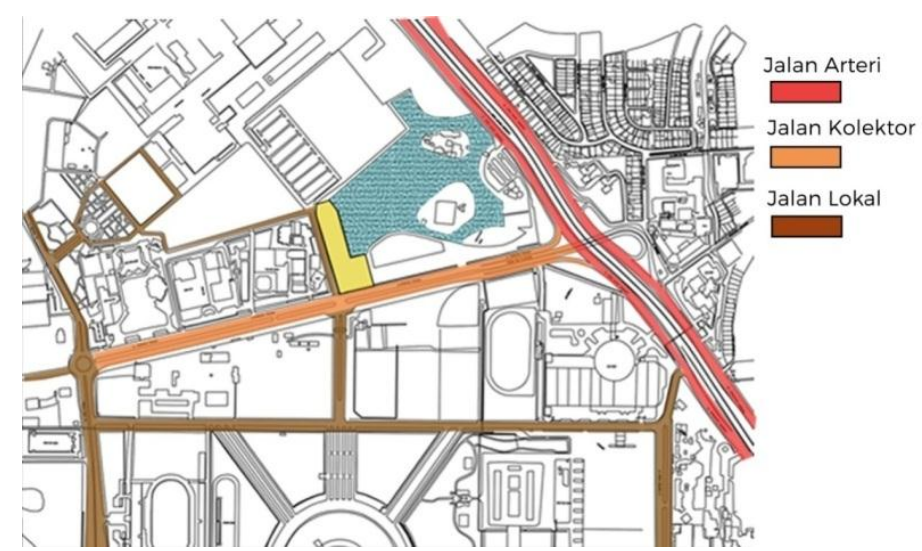

Gambar 6. Klasifikasi Kelas Jalan di Sekitar Tapak-Akses Pedestrian Sumber:Olahan penulis, 2018

\section{Konsep Gubahan Massa}

Pembentukan massa dibentuk dengan melihat dari bangunan sekitar kawasan yang sangat simetris. Untuk membuat bangunan yang berbeda maka pendekatan yang dilakukan adalah melakukan studi bentuk yang asimetris. Bentuk dasar diambil dari bentuk tapak yang sudah tidak simetris, dari bentuk tapak dikembangkan dengan melihat kondisi tapak eksisting yang penuh dengan kontur.

Bentukan massa diorientasikan untuk memaksimalkan view ke dalam tapak yaitu view terhadap danau Taman Ria. Di bagian depan massa juga dibentuk sudut lancip untuk membuat kesan iconic kepada para pengunjung yang masuk ke dalam tapak. Peletakan massa disesuaikan agar mempunyai aksis yang sama dengan Gelora Bung Karno (GBK) agar bangunan dapat dilihat dari GBK, dengan terlihatnya bangunan dari GBK dapat mengundang wisatawan yang sedang berwisata di GBK.

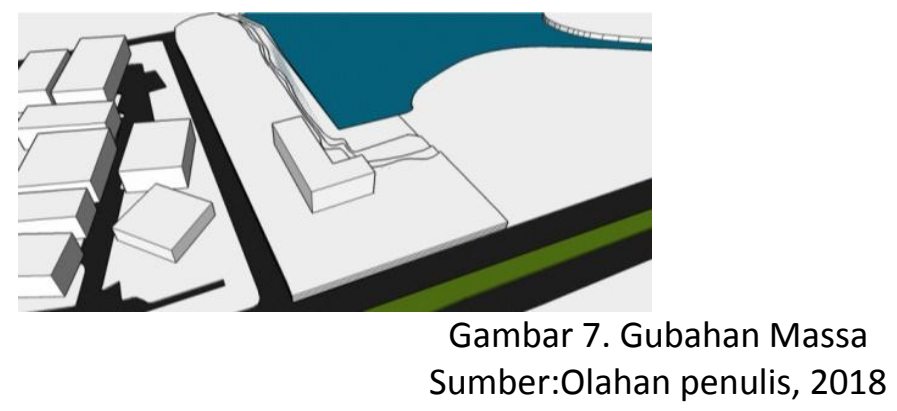

\section{Konsep Perancangan Ruang Luar}

Tapak ini mempunyai dua zonasi ruang luar yaitu zona hutan kota dan zona waterfront (tepian air). Di antara kedua zona ini terdapat kontur yang memisahkan kedua zonasi ini. Pada bagian kontur ini ditanami tanaman Palem yang berperan sebagai pagar antara kedua zona ini, Selain untuk membatasi, pohon Palem ini juga memperkuat suasana ketika berada di tepian air. 


\section{Gambar Perancangan}

Berikut hasil akhir dari perancangan Taman Rekreasi dan Pusat Informasi Pariwisata di Jakarta.

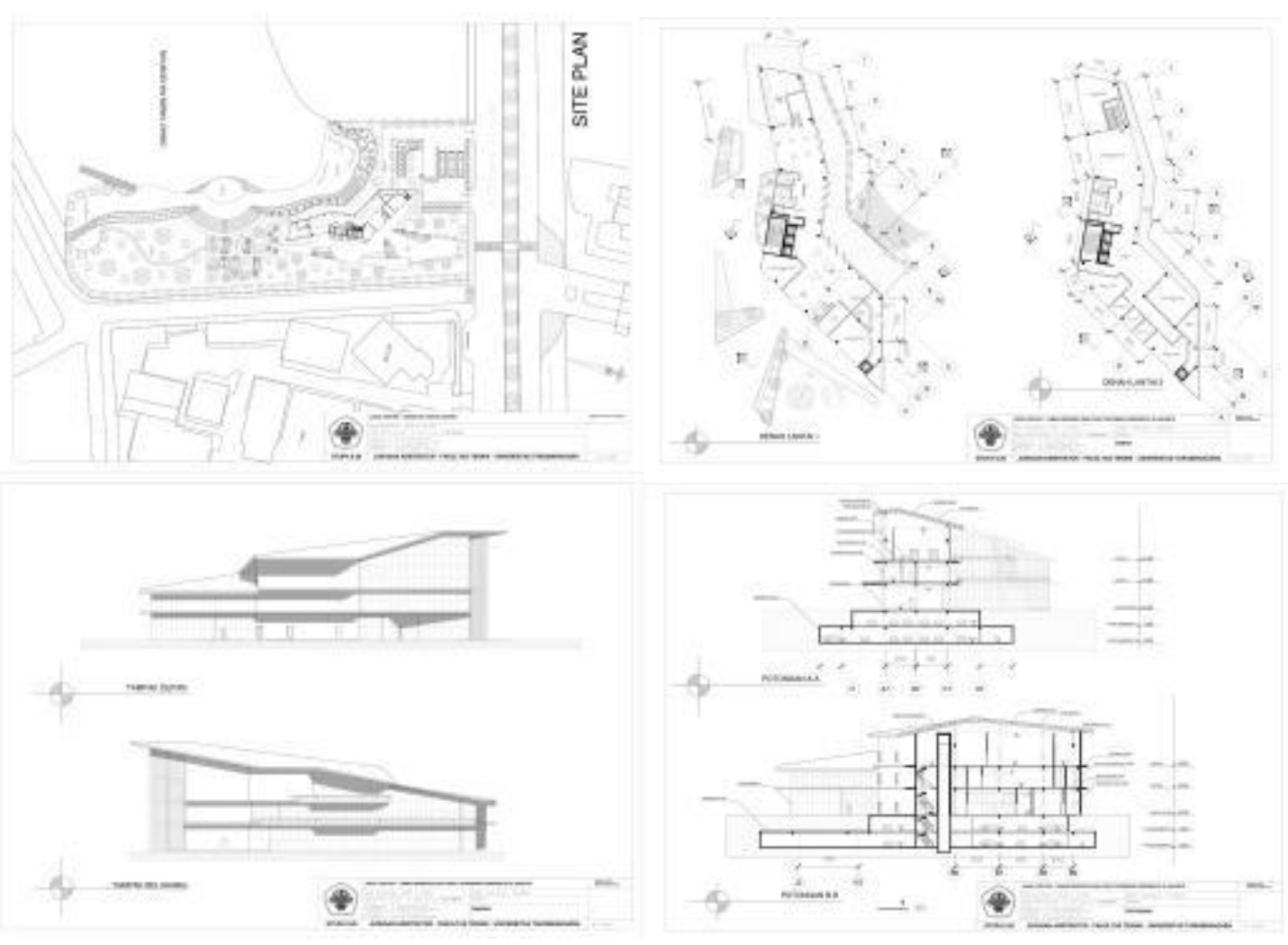

Gambar 8. Gambar Hasil Rancangan

Sumber:Olahan penulis, 2018

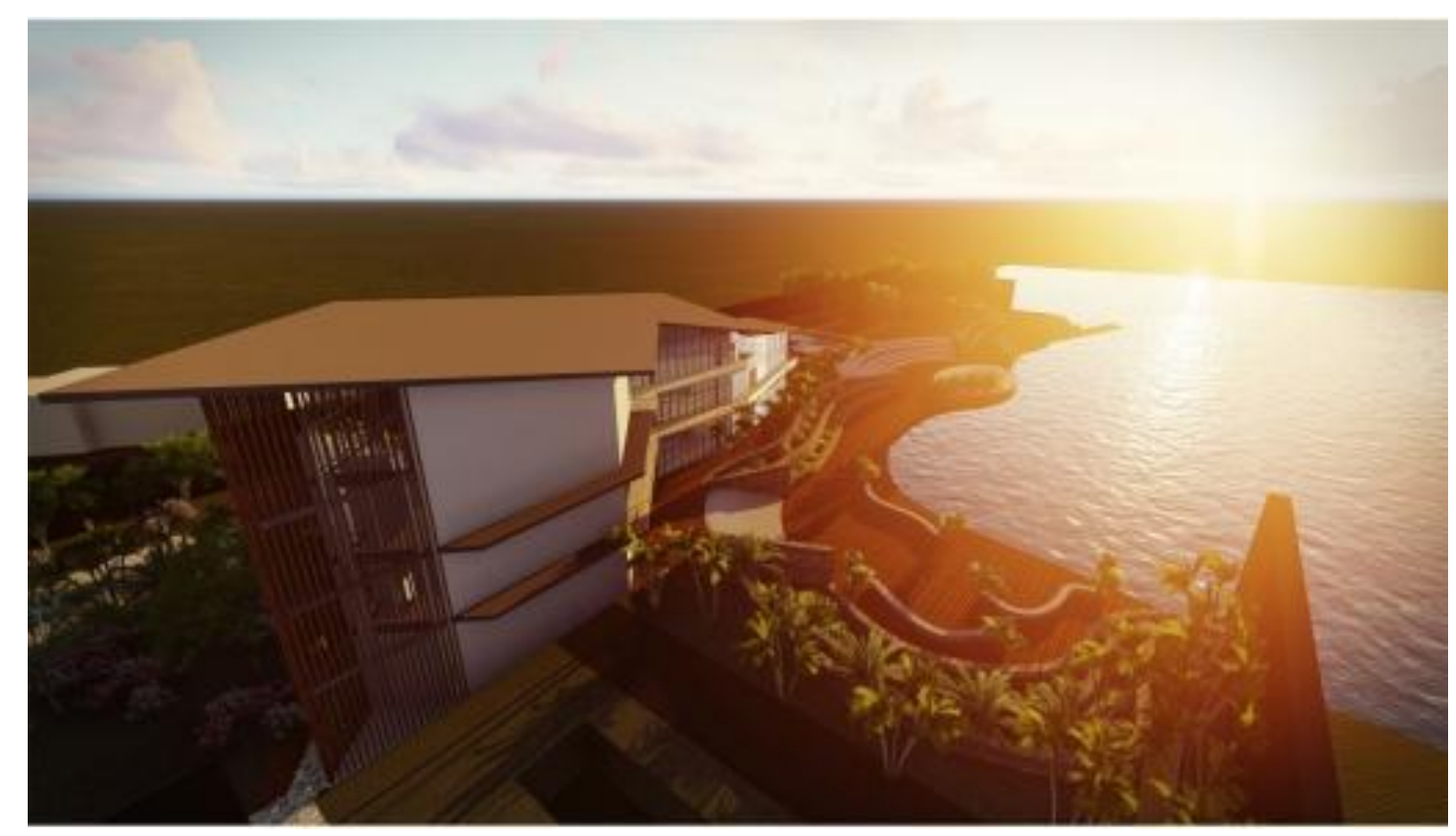

Gambar 9. Gambar Perspektif Eksterior

Sumber: Olahan penulis, 2018 


\section{KESIMPULAN DAN SARAN}

Dengan adanya sebuah pusat informasi di sebuah kota metropolitan akan membantu para wisatawan untuk menemukan objek wisata yang baru dan memberikan informasi yang valid mengenai jenis wisatanya. Untuk itu keberadaan visitor center di sini menjadi sangat penting, karena visitor center berfungsi sebagai fasilitas untuk wisatawan dan objek wisata itu sendiri.

Dalam merancang sebuah visitor center hal penting yang perlu diperhatikan pertama Visitor Center mempunyai bentuk yang unik dan berbeda dari lingkungan sekitarnya. Kedua dalam menyusun program aktivitasnya visitor center mempunyai program primer dan sekunder, program primer dari visitor center ini adalah sebuah pusat informasi, program sekunder ini bersifat lebih fleksibel, sebaiknya dibuat dengan menganalisa potensi yang dimiliki dari kawasan itu sendiri dan ditambahkan unsur kebudayaan lokal.

\section{UCAPAN TERIMA KASIH}

Penulis ingin mengucapkan terima kasih kepada Dosen Pembimbing Utama, Dosen Pembimbing Pendamping, Dosen mata kuliah dan pembimbing lainnya, Ketua Jurusan Arsitektur dan Perencanaan Fakultas Teknik Universitas Tarumanagara, dan Pihak-pihak lainnya yang telah memberikan pengarahan, petunjuk dan bimbingan yang memungkinkan terselesaikannya penyusunan artikel Jurnal STUPA.

\section{REFERENSI}

Specht, Jan. (2014). Architectural Tourism Koolhas, Rem. (1994). Delirious New York Wirawan, Adi. (2016). Perancangan Tourism Center di Singosari Bagus Rai Utama, I Gusti .(2012). Fungsi dan Perencanaan Visitor Center Pariwisata Daerah. diperoleh dari: https://tourismbali.wordpress.com/2012/02/10/fungsi-dan-perencanaanvisitor-center-pariwisata-daerah/

https://www.theguardian.com (2017, 1 Oktober). The Bilbao effect: how Frank Gehry's Guggenheim started a global craze. Diperoleh 10 juli 2018, dari https://www.theguardian.com/artanddesign/2017/oct/01/bilbao-effect-frank-gehryguggenheim-global-craze 